Marie-Laure Ryan*

\title{
Narrative mapping as cognitive activity and as active participation in storyworlds
}

https://doi.org/10.1515/fns-2018-0020

Abstract: Ever the devil's advocate, Richard Walsh argues in a 2017 article that drawing maps based on narrative fiction is a meaningless activity, because (1) narrative cognition is temporal and not spatial; (2) narrative fiction does not project worlds in any experiential sense of the term (i.e. worlds as immersive environments) but only "worlds" as textual constructs, as products of écriture; and (3) reading should lead to meaningful interpretations, and inferences should be limited by a principle of relevance. His example of futile map-making is the floor plan which is included in the English editions of Alain Robbe-Grillet's La Jalousie but is absent from the original French edition. In this article, I argue that narrative cognition is not a specialized ability distinct from the forms of cognition that we use in practical life, but rather, the product of these abilities; and I defend the validity of narrative mapping as way to engage the imagination with - yes - a storyworld. This is not to say that narrative understanding requires the drawing or mental contemplation of a comprehensive representation of the storyworld; usually the formation of partial mental maps is sufficient to follow the plot. But for some readers (among them Nabokov) drawing graphic maps is a way to engage the imagination with the storyworld and to enhance comprehension. This map-making activity can go far beyond making sense of the text and become an autonomous activity comparable to writing fan fiction. To support this view, I invoke the numerous maps found on the Internet for narratives ranging from Proust's A la recherche du temps perdu to Tolkien's Lord of the Rings. While the strictly "textualist" aesthetics of orthodox literary theory would regard these maps as frivolous, a world-oriented approach regards the urge to map and diagram as a legitimate form of active participation in narrative, because, while you can imagine too little to appreciate these texts, you cannot imagine too much.

Keywords: mental maps, narrative cartography, spatial cognition, immersion, storyworlds

*Corresponding author: Marie-Laure Ryan, Bellvue, Colorado, USA, E-Mail: marilaur@gmail.com 
In 1956, Alain Robbe-Grillet published a manifesto, “A Path Toward a New Novel," in which he outlined his vision of the novel of the future. This novel had to get rid of a number of outdated elements that had been a staple of the realist (or, for Robbe-Grillet, "bourgeois") novel: characters, story (or plot), political engagement, and (in an admonition aimed at critics much more than at writers), a distinction between form and content. So, what was left for the novel to be made of? In a move that echoed or anticipated the radical "textualism" of New Criticism, Postmodernism and Deconstruction, Robbe-Grillet claimed that the novel should not depict the adventures of characters, but rather, the adventures of écriture. "The entire interest of the descriptive pages - that is, man's place in these pages - is therefore no longer in the thing described, but in the very movement of the description" (1965: 148). And: "When [the author; here Robbe-Grillet speaks for himself] thinks of a future novel, it is always a way of writing which first of all occupies his mind... What will happen in the book comes afterwards, as though secreted by the style itself" (1965: 44). A year later, in 1957, Robbe-Grillet published a novel that put to work, as far as it would go, the principles stated in his manifesto. This novel is La Jalousie (Jealousy), and if it is still read today, it is not as an auspice of things to come, but as the purest manifestation of the New Novel, a movement that quickly fell out of fashion but raised important narratological and aesthetic questions.

La Jalousie is a tour de force of écriture. It is narrated in the third person by an anonymous narrator who limits himself to external focalization, with no access to other people's thoughts (nor indeed to his own). This characterization would suggest that La Jalousie is a classic case of extradiegetic heterodiegetic impersonal narration, but according to critical consensus, the narrator is in fact a jealous husband who obsessively observes his wife's behavior, his view often limited to what can be seen through various openings, such as window panels or the open latches of shutters, appropriately called "jalousies” in French. (The pun totally disappears in English.) In addition to the narrator's spectral presence, there are a few other characters, like his wife, A. (the lone initial suggesting lack of human density), a neighbor, Franck, who visits the couple regularly on their banana plantation somewhere in the colonies for drinks or for dinner, and Franck's wife, Christiane, who remains at home and never appears in the narrator's field of vision. No mention is ever made of the husband's suspicion that A. may have an affair with Franck, but this psychological explanation (which goes against RobbeGrillet's principles) gives meaning and unity to a text that consists almost exclusively of spatial descriptions. Here is an example:

[F]rom the far side of the bedroom the eye carries over the balustrade and touches ground only much further away, on the opposite slope of the little valley, among the banana trees of 
the plantation. The sun cannot be seen between their thick clusters of wide green leaves. However, since this sector has been under cultivation only recently, the regular crisscrossing of the rows of trees can still be clearly followed. The same is true of almost all the property visible from here, for the older sectors - where confusion has gained the ascendency - are located higher up on this side of the valley, that is, on the other side of the house.

It is on the other side, too, that the highway passes, just below the edge of the plateau. The highway, the only road that gives access to the property, marks the northern border. A dirt road leads from the highway to the sheds and, lower still, to the house, in front of which a large cleared area with a very slight slope permits cars to be turned around. (Robbe-Grillet 1959: 40)

This passage reads like instructions for drawing a map, and indeed some readers (including myself) will be strongly tempted to do so. What else can one do with a novel that stubbornly refuses to reveal the private thoughts of characters, offers no answer to the question of whether or not A. and Franck are lovers, and revisits the same scenes over and over again, jumping capriciously along the time-line and stalling any forward movement? Through their reference to absolute points of orientation, namely East, West, North and South, as well as their use of relative ones, such as left and right, the spatial descriptions of La Jalousie make it possible to reconstitute fairly exactly the floor plan of the house and the configuration of the landscape that surrounds it. A map of the house is indeed included in the English translation of the novel, but not in the original French text. There is no indication of who produced the map, and of whether its inclusion was approved by the author. When I read the French version in preparation for this article, I decided to draw a map without consulting the one of the English version, to see if the two coincided. The instructions for drawing the map are scattered throughout the novel, and as I went along, I made a few mistakes and had to reposition certain rooms, but I came upon passages that made everything fall into place, and my map ended up similar to the one in the book, which is shown in figure 1.

In a 2017 article titled "Beyond fictional worlds: Narrative and spatial cognition," Richard Walsh expressed objections to the map as a meaningful reading of La Jalousie. It could be argued that its inclusion deprives readers of the pleasure of creating it themselves but this is not Walsh's point. Rather, he regards mapping as a frivolous activity. To push his point he engages in what he terms "perverse" readings of La Jalousie. First, he expands the map in three dimensions, building a computer-aided model of the house. Second, he uses inferences from the text to determine the exact date of the various episodes of the novel. Assuming (on textual grounds) that the setting is not Africa he locates it in Martinique, an oversea French territory where bananas are grown (though La Reunion, an island in the Indian ocean, is also compatible with the text). The novel begins with this description: "Now the shadow of the column - the column which supports the 
southwest corner of the roof - divides the corresponding corner of the veranda into two equal parts" (1959: 39). Reading the shadow as a sundial, and using "modern three-dimensional computer modelling," combined with "geo-location," Walsh concludes on the basis of this information that "the opening of the novel is at 2.19 p.m. on the $26^{\text {th }}$ of March" (Walsh 2017: 471). Another description of the shadow (Robbe-Grillet 1959: 100-101) leads him to claim that the scene must take place on the $5^{\text {th }}$ of April. Such precise dating would require a much more exact specification of the house's coordinates than the assumption that it located in Martinique, as well as an exact knowledge of the house's orientation. Who knows if it is perfectly aligned on an East-West axis? Walsh is obviously pulling his reader's leg, and though he admits enjoying the calculations, he proposes his conclusions not as a legitimate reading but as a demonstration ad absurdum of the irrelevance of the map of the house. Though this map is based on rigorous textual information, in contrast to the determination of the time and day of selected scenes, Walsh is telling us that there is a slippery slope between these interpretations. In other words, if you think it is ridiculous to compute time on the basis of the shadows, it is also ridiculous to draw maps of a space that does not exist. Of the time-reconstruction Walsh writes: "I could go further (I'm tempted to do so), but perhaps that's enough now. These revelations, however startling, are clearly not a significant advance in scholarship of the novel" (2017: 471). About the three-dimensional modelling of the house, Walsh writes: "While I can find no interpretive use for such detailed modelling of the spatial environment represented by the novel, it is undeniably an inferential process that is textually wellfounded" (2017: 470). But most revealing of his position are his comments on the flat map: "This diagram does not only express a certain interpretative stance towards the novel, it also - according to many narrative theorists, at least encapsulates something intrinsic to the comprehension of narrative fiction. Put succinctly, this is the view that reading fiction requires us to extrapolate the 'world' of the narrative, in order both to understand the story and to engage with it imaginatively, thus providing for emotional involvement and 'immersion"” (2017: 462). If the map is objectionable, then, it is because it supports a view of narrative fiction as immersive world-creation, a view endorsed by many scholars, including myself (Ryan 2016), but which Walsh wants to challenge. Walsh's opposition to this model in general, and to the map in particular, is based on the following assumptions:

1. Narrative cognition is temporal and not spatial. "Narrative cognition is the semiotic articulation of linear temporal sequence (you'll note that unlike most such definitions, it avoids mention of events, agency, causality, or even representation)" (Walsh 2017: 473). According to this definition, the map cannot capture what makes a text a narrative, since it is the product of spatial cognition. To be 
fair to Walsh, he does not exclude spatial cognition from being involved in the cognitive processing of narrative. Narratives, after all, comprise both descriptions and narration proper (i.e. reports of events that occur in time). But for a text to be narrative on the macro-level, spatial cognition must, presumably, be subordinated to narrative cognition.

This notion of narrative cognition is problematic. It suggests that the ability to produce and understand narrative is a specialized ability that could be located in some areas of the brain by using an imaging technology. I would rather suggest that this ability is the product, or convergence, of many different forms of cognition that we also apply in everyday life. A brain in a vat would be unable to narrate or to understand stories; it is our embodied life experience that enables us to do so. "Narrative cognition," then, is a convenient shortcut for a variety of mental operations, not a term to be taken literally as designating a distinct mode of cognition.

Moreover, Walsh's conception of narrative cognition as purely temporal, yet as independent from "events, agency, causality, or even representation" makes one wonder what the object of this so-called narrative cognition is. Is it the effect of the temporal effects of suspense, curiosity and surprise, which Meir Sternberg (1992) regards as constitutive of narrativity? Then it depends crucially on the representation of events, agency and causality, despite Walsh's attempt to eliminate these factors from consideration. A text can represent space independently of time by limiting itself to descriptions, but the reverse does not occur: while there are narratives that seem to give little consideration to space (for instance "the king died, then the queen died of grief"), stories always concern concrete objects that exist in space. When a text has virtually no temporal development, in other words when its narrativity is very low, as is the case with Robbe-Grillet's $L a$ Jalousie, it redirects attention to space. If there is a novel that can be made more interesting by mapping its world, it is La Jalousie. Walsh's rejection of the map of La Jalousie in the name of "narrative cognition" is therefore highly paradoxical.

2. Narrative fiction does not depict worlds. The title of Walsh's article, "Beyond fictional worlds," makes clear his intent to eliminate the notion of world from narrative semantics and from the theory of fictionality. So does his use of scare quotes to surround the term in the statement quoted above (from p. 462). In so doing Walsh plays the devil's advocate, for the notion of fictional world or storyworld is currently enjoying great popularity in both the theory of fictionality and cognitive narratology (Wolf 2012, Ryan 2016, Herman 2009). A fictional text can be defined as a text that refers to a world other than the actual world, and a narrative, in the words of David Herman, as a "blueprint for constructing a world" (Herman 2009: 105). The notion of world also offers a convenient target for the experience of immersion, which has received increasing attention since digital 
technology and its dream of virtual reality brought attention to it (Ryan 2016). For readers to get immersed, there must be an environment to be immersed in, and despite the maritime metaphor, this environment is not the sea but a world populated with objects and characters who attract the reader's interest. And finally, "world" provides a basis for the phenomenon that has been variably described as transfictionality, transmedia storytelling, or shared universe, the phenomenon of a content shared, expanded, or revised by multiple texts, and adapted to multiple media (Jenkins 2006, Saint-Gelais 2011). Standard examples of this phenomenon are the franchises Lord of the Rings or Star Wars or the Jane Austen complex. Earlier, it was Homeric tales or the cycle of Arthurian romances. How could one refer to what these groups of texts have in common, if not with a spatial concept such as world or universe that serves as a container, or setting, for multiple stories?

One of the premises of the use of the notion of world to refer to that which narrative fictions (or narratives in general) bring to the imagination, is that a world contains more than an individual text can show. This allows the imagination to form mental pictures of the setting, of the characters, and of their actions and movements that go beyond textual descriptions. Another premise is that readers imagine fictional worlds as existing independently of the text that describes them, even though they know this to be false: objectively speaking, fictional worlds are the product of fictional texts. This imagined autonomy of fictional worlds justifies the project of mapping, for a map is in essence a representation of an external reality; but it runs afoul of the teachings of textualist literary theory, which tells us that literary texts are really about language and that there is nothing outside the text, except for intertextual allusions to other texts. By rejecting the notion of world, then, Walsh implicitly adheres to a version of textualism. Together with the notion of world, he also rejects immersion as a valid type of textual experience: immersivity, for Walsh, is a property of certain media, such as VR or maybe film, not a property of certain representations (2017: 476). If Walsh is right, it is hard to explain how people can become immersed in novels, since language speaks to the mind rather than to the senses and is therefore the least inherently immersive of narrative media.

\section{The reading of literary texts should advance scholarship and support} legitimate interpretations by obeying a principle of relevance. Drawing a map of La Jalousie fulfills neither of these goals; it is therefore a futile project. Walsh adheres to a theory of reading that preaches parsimony. He rejects what I have called the "principle of minimal departure" (henceforth MD; Ryan 1991), which instructs readers of fiction to use their experience of the real world in their construction of fictional worlds and to make only those changes mandated by the text. According to Walsh, minimal departure allows the import of too much 
information because it does not tell readers which inferences are useful and which are not. Many gaps, he argues, cannot be filled in on the basis of textual information nor on the basis of real world experience. An example of such a gap is "how many times did Joseph $\mathrm{K}$. in Kafka's The Trial consider writing a short account of his life?" (Walsh 2006: 17). (Several times says the text.) In defense of $\mathrm{MD}$, however, it can be argued that the principle does not tell readers what they must do, but only what they can and cannot do. There is a specific number of times K. wanted to write an account, and according to MD this number cannot be Pi or the square root of -1 , but readers are free to estimate this number as any integer, or more likely, to regard it as missing information.

As an alternative to minimal departure, Walsh proposes a view of narrative (or rather, fictional) meaning based on the linguists Dan Sperber and Deirdre Wilson's theory of relevance (Walsh 2006: 23-29). According to this theory, when they interpret an utterance, hearers will draw as many inferences as needed to attribute to the speaker an intent that makes sense in the current context. (This is a vastly simplified formulation of a complex theory.) A prime example is the interpretation of the sentence "can you pass the salt?" during dinner as a request rather than as a question about the hearer's ability to pass the salt. Once the speaker's practical intent has been recognized, there is no need to make further inferences; this conception of meaning sets therefore definable limits to the hearer's interpretive activity. In the case of passing the salt, relevance is fairly easy to establish, since it concerns practical action, but how can it be defined in the case of literary fiction, a type of utterance detached from any pragmatic context, and concerning, for the most part, non-existing entities rather than proposing information about the real world? If relevance could be rigorously defined and unambiguously identified for literature, there would be no need to look for additional meanings once a relevant interpretation had been reached, and endless debates about validity in interpretation could be avoided.

The restrictive aspect of Walsh's relevance theory contrasts with the leniency of MD: whereas Walsh's relevance theory warns readers against unnecessary inferences, MD tells readers: "you can imagine too little, but you cannot imagine too much." Under a strict theory of relevance, the map is useless, because the text can easily be read and appreciated without it; under minimal departure, the map is acceptable, because it is compatible with both textual information and Euclidian geometry, which, according to cognitive scientist Michel Denis (2018:16), controls our perception.

Let us now turn to the issue of how and why some readers create maps of storyworlds. Maps can relate to narrative texts in various ways: some are built by authors as a tool to ensure logical coherence, but are kept out of the text; some are author- or illustrator-created, and inserted in the text as a cognitive aid; some 
are illustrator-created, and inserted in certain editions of the text by the publisher, again as guide to the reader; and finally, the type that interests us here, some are created by the reader in response to the text. The map of La Jalousie is technically an editor-map that spares the reader the task of building it, but since a perfect copy of this map can be constructed from the French text, in which it does not appear, it can also be regarded as an ideal reader-map.

The process of mapping storyworlds bears some analogies with the formation of cognitive maps of the real world. A cognitive map is a mental representation that enables people to orient themselves in real space; it is based on a person's embodied experience. In his book on spatial cognition, Michel Denis mentions a useful distinction made by the mathematician Henri Poincaré between an infinite, three-dimensional, and continuous "geometric space" and a limited, two-dimensional, and discontinuous "perceived space." The claim that perceived space is two-dimensional may come as a surprise, but to the eye, only height (y axis) and width ( $\mathrm{x}$ axis) are immediately perceivable; the third dimension, depth ( $\mathrm{z}$ axis), can only be guessed. Distance is estimated in function of perspective and embodied action: "The innovative view introduced by Poincaré," Denis writes (2018: 9, quoting Poincaré) "is that when we localize an object in a given point of space, 'it simply means that we represent to ourselves the movements that must take place to reach this object." Or, to quote Poincaré directly, "It is our body that serves us, so to speak, as a system of axes of coordinates." When we turn our perception into a map, that is to say, into geometric space, we replace the $\mathrm{x}-\mathrm{y}$ axis of our visual field with an $\mathrm{x}-\mathrm{z}$ view that shows the distance our body has to travel to reach remote points, but we sacrifice the vertical dimension. This dimension is not overly useful, except for pilots and alpinists, since our bodies move on a largely flat plane. ${ }^{1}$

Cognitive maps of storyworlds differ from cognitive maps of real space in that they are built on the basis of selected textual information (or visual, in the case of film, though film is far less conducive to mapping than literature) rather than on the basis of directly perceived space. The spatial information provided by the text can represent the experience of three kinds of bodies: the bodies of the characters whose movements and relations to objects are being described, the body of the first-person narrator, or the experience of the purely virtual body of the thirdperson, impersonal narrator, which is nothing more than a point of observation. As purely mental representations, cognitive maps are evanescent; the textual information on which they are based may be sparse, widely scattered in the text,

$1 \mathrm{x}$-y mappings are called elevations; y-z mappings are rare; they can be used to represent the contour of mountains. 
or on the contrary so abundant that the reader has trouble keeping it all in memory. While some readers are satisfied with partial representations of the storyworld that quickly replace each other in short-term memory, others will use pen and paper to create comprehensive and durable narrative maps.

Drawing graphic maps of storyworlds is not for everybody: it requires a certain type of reader, and a certain type of text. In Lectures on literature, Vladimir Nabokov describes "the good reader" (i.e. himself, a reader with a compulsive need to map and diagram literary texts) through features that can also be ascribed to what may be called the "cartographic reader":

1. The cartographic reader is a re-reader. You can't draw a map the first time around. During the first reading you read for the plot, swept by the flow of time, and eager to find of how the story ends. This is not meant as a dismissal of first time reading: temporal effects such as suspense, curiosity and surprise, which are created by the particular timing of the release of information, are an essential aspect of narrative aesthetics. In a first reading, we acquaint ourselves gradually with a story and with its world. "But at a second, or third, or fourth reading we do, in a sense, behave towards a book as we do towards a painting" (Nabokov 1980: 3): the element of time disappears, and we can devote our full attention to the configuration of space, and to how this configuration affects the behavior of characters.

2. The cartographic reader is a visualizer. As Nabokov writes: "We should see things and hear things, we must visualize the rooms, the clothes, the manners of an author's people. The color of Fanny Price's eyes in Mansfield Park and the furnishing of her cold little room is important" (Nabokov 1980: 4). Visualizing storyworlds means knowing how objects relate spatially to each other and being able to imagine how characters manipulate these objects and move among them.

3. The cartographic reader reads with his whole body: "a wise reader reads the book of genius not with his heart, no so much with his brain, but with his spine" (Nabokov 1980: 6). I assume that "spine" stands here for an embodied experience of narrative space: the purpose of mapping is to facilitate the reader's selfprojection into the storyworld and the mental simulation of the gestures of characters.

4. The cartographic reader regards the text as an enigma to be deciphered. Nabokov conceives his course as "a kind of detective investigation of the mystery of literary structures" (Nabokov 1980: frontispiece). Similarly, the cartographic reader brings to the graphic (or mental) construction of space the zeal of a detective. The clues are contained in elements that would be overlooked without the attempt to map the storyworld. 
To these conditions I will add two of my own:

5. The cartographic reader is not satisfied with a collection of partial views of storyworld space; he or she wants individual descriptions to fit together into a global representation. This global view is particularly useful to the plotting of the itineraries of characters, especially when these itineraries end in convergence or divergence.

6. The cartographic reader is attentive to the strategic dimension of space. In Ryan, Foote and Azaryahu (2016: 39-43), the authors contrast the emotional relations that connect us to places with the strategic attitude that regards the configuration of space as a means to achieve goals, or an obstacle to plans. Just as military leaders use maps to plan battle moves, cartographic readers draw maps of the storyworld to understand how the particularities of space such as the arrangement of furniture in a room, the floor plan of a house, or the contour of the terrain - affect the behavior of characters.

Putting these ideas into practice, the handwritten notes and the personal copies of the texts used by Nabokov to prepare his lectures contain sketches of just about everything that can be drawn, mapped or diagrammed. There are maps of England locating the action of Jane Austen's Mansfield Park and of Charles Dickens' Bleak House; a map of Dublin showing the respective itineraries of Leopold Bloom and Stephen Daedalus in Joyce's Ulysses; an elevation sketch of the house of Leopold Bloom; partial maps of Proust's Combray (partial because the text gives very scant spatial information); diagrams of the themes of Bleak House and of the tripartite structure of Metamorphosis; drawings of the hat of Charles Bovary as described by Flaubert in Madame Bovary and of the insect that Gregor Samsa turns into in Kafka's Metamorphosis; floor plans of the house in Mansfield Park and of the apartment in Metamorphosis. These sketches reveal a stubborn will to pierce the visual secrets of the texts and to uncover their spatial logic. For instance, the fact that Leopold Bloom's house has three stories on the street side, but four, with an underground level on the courtyard side, explains how Bloom gets into the house without a key when he returns home early in the morning. The shape of the insect into which Gregor Samsa is metamorphosed can be derived from the description of his efforts to turn over in his bed or to open the door of his room. The layout of the apartment, the position of the furniture and the direction in which doors open has strategic importance for how Gregor learns to use his insect body, while keeping it hidden from his mother to spare her a horrible sight. Kafka must have worked from a very precise plan of the flat. 


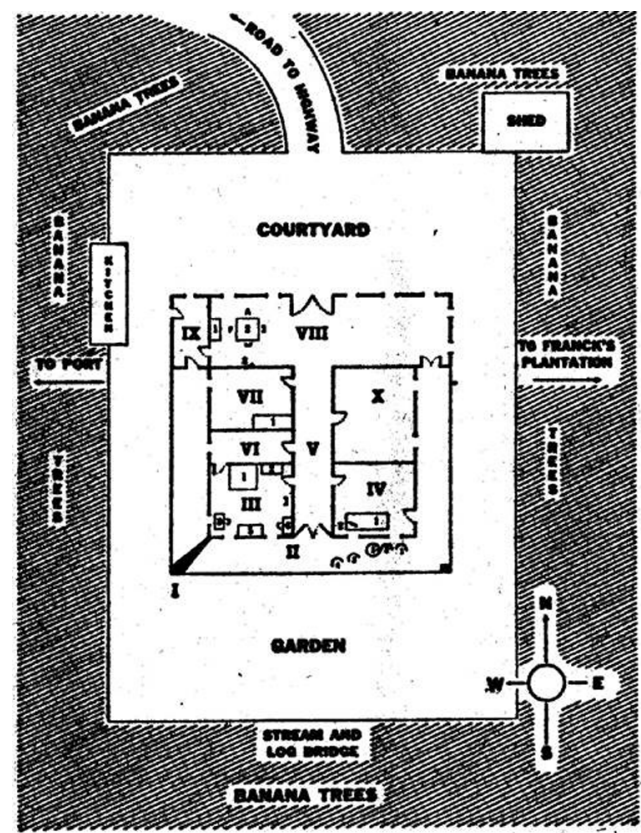

\section{LEGEND}

I. Southwest pillar and its șadow at the beginning of the novel.

II. Veranda: 1) Franck's chair. 2) A . . .'s chair. 3) Empty chair. 5) Cocktail table.

III. A. . .'s room: 1) Bed. 2) Chest. 3) Dressing table. 4) Writing table. 5) Wardrobe.

IV. Office: 1) Desk. 2) Photograph of A...

V. Hallway

VI. Bathroom

VII. Small bedroom: 1) Bed.

VIII. Living room - dining room: 1) Sideboard.

2) Table. 3) Mark of centipede on wall. IX. Pantry.

$\mathrm{X}$. Storage room or other (not described).

Figure 1: The map in the English translation of Robbe-Grillet's La Jalousie.

This strategic function is probably the main reason for drawing maps of storyworlds, but it is not the only one. Let us return to La Jalousie. The map can be used as an aid in visualization, by offering a canvass on which the reader mentally places characters, imagines what objects surround them, and follows their movements. It can also tell whether or not the space of the storyworld is coherent. Robbe-Grillet is known for creating logically impossible storyworlds ${ }^{2}$ (if the term of world can still apply to contradictory sets of propositions), but against expectations, the space of La Jalousie is perfectly consistent. Without drawing a map, it would be impossible to reach such a conclusion. Maps can suggest a symbolic geography, by showing where the action takes place, and which areas of the storyworld remain narratively uncharted. For instance, in La Jalousie, the map localizes the action in the front and the back of the house, in spaces that play a clearly defined role in the life of the characters, but the characters never enter the rooms in the middle of the house (VI, VII and X on figure 1), and the function of at least one of these rooms (X) remains obscure. The visible thus surrounds a core of invisibility. The map also reveals the social organization of space: it is not

2 Contradictions occur in Robbe-Grillet's La Maison de rendez-vous and Dans le labyrinthe. 
insignificant that the house in La Jalousie contains no kitchen and that the food comes from a mysterious elsewhere, brought over by black servants who also come from the outside. The dynamics of the mapping action can reveal the author's descriptive strategy. Some storyworlds can be mapped right away, and readers never needs to correct their mental or graphic representation, while others can only be represented gradually, forcing readers to revise and erase and to leave blank areas on the page. ${ }^{3}$

Whether mental or graphic, narrative maps can refer to various zones of space. Barbara Tversky (2003), a psychologist who specializes in spatial cognition, distinguishes four regions of space, made accessible by different forms of cognition: (1) Space of the body - the area we can reach physically from our current position; (2) Space around the body - areas we can see from our current position; (3) Space of navigation - areas we can visit through presumably unassisted corporeal movement. (4) Space of graphic representation - areas we know through maps, such as the shape of a country (summarized by Denis 2018: 52-53). Narratives differ from each other through the relative prominence of these spaces, but all four play a role in La Jalousie. Space 1, the corporeal space of characters, comes into play whenever the narrator, driven be jealousy, focuses on A's handling of objects, such as writing a letter (to whom?), combing her hair in her room (does she want to please somebody?), or offering a drink to Franck. As this last example suggests, space 1 can include other characters, when their bodies are in close proximity. Though this space is too dynamic to be mapped, it can be visualized by the reader through the mental simulation of the character's gestures. While space 1 corresponds to A.'s private sphere, space 2 is delineated by the narrator's field of vision. Most, if not all of the text describes what the narrator can see from a fixed point of view. This vision is obstructed by walls, window frames, and the latches of the "jalousies" when the narrator looks at the inside from the outside, or at the outside from the inside, but nothing blocks the eye when he looks at the surrounding landscape from the terrace, and this

3 An example of passage that enables the reader to map the storyworld right away, without corrections, is the beginning of Flaubert's Herodias:

In the eastern side of the Dead Sea rose the citadel of Machaerus. It was built upon a conical peak of basalt, and was surrounded by four deep valleys, one on each side, another in front, and the other in the rear. At the base of the citadel, crowding against one another, a group of houses stood within the circle of the wall. A zigzag road, cutting through the rocks, joined the city to the fortress, the walls of which were about one hundred and twenty cubits high, having numerous angles and ornamental towers that stood out like jewels in the crown of stone overhanging an abyss. (Quoted from Denis 2017, 133).

Flaubert, who used sketches to produce this passage, rewrote it fourteen times (Denis 2017, 133134). 
landscape can be described in panoramic, almost map-like fashion. The floor plan represents space 3, the space of the character's routine movements. Walsh observes that the map in the book could easily be extended to cover the whole of space 2, so precise are the landscape descriptions, but an extended map would not represent the characters' zone of corporeal mobility, for we never see them venture beyond the house and its immediate surroundings. As for space 4, it stretches from the couple's and Franck's plantations to a harbor located several hours away by car on bad roads. A. and Franck take a shopping trip together to the harbor, where they are retained for the night, and this trip arouses, or increases, the narrator's suspicion of an affair between the two. But since the narrative point of view never leaves the house, we only learn about the trip through A.'s and Franck's conversation, as well as from the narrator's wait for them to return as night descends on the landscape. It would be pointless to map this extended space because its exact configuration is left unspecified, in stark contrast to the precise descriptions of the three other zones.

So far, I have argued for the validity of narrative maps as means of interpretation, but I would like to conclude with a defense of what textualist literary theory would regard as their irrelevance. As already noted, the purely text-centered approach to literature, which conceives the literary text as a self-referential network of internal and intertextual relations is currently being challenged by a world-based approach that emphasizes, on the side of the author, the faculty of invention, i.e. of what J.R.R. Tolkien (1997) calls "secondary world creation," and on the side of the reader, the cognitive processes involved in the act of imagining the world created by the text. Fictional worlds are increasingly shared by multiple texts, and multiple media. As they expand through seriality, transmediality and transfictionality, these worlds become habitats where we want to return over and over again, spaces of exploration, and sources of collective experiences that create cultural bonds. There are lots of things that people do with storyworlds, especially with the extended storyworlds of popular culture, that would not meet the approval of textualism: participating in their creation by writing fan fiction, dressing up as characters in cosplay events, manufacturing three-dimensional versions of fictional objects, collecting action figures representing characters, walking literary trails, visiting the real-world locations of imaginary events, and last but not least, creating maps of storyworlds. These readers put into practice the principle mentioned above: you can imagine too little about storyworlds, but you cannot imagine too much.

The Internet, by making the work of both professionals and amateur readers available, gives a true measure of the importance and variety of narrative cartography. Take Flaubert's Madame Bovary, which is set in Normandy, in both realworld towns (Rouen and Tostes) and an invented one (Yonville). Googling " $M a$ - 
dame Bovary, maps”, will produce actual geographic maps of Normandy, Rouen and Tostes, Flaubert's sketch of Yonville, and a more professional-looking map of Yonville from the Musée Bovary in Ry, probably based on Flaubert's sketch, that links points of the map to photographs. Or if you google "Proust, Combray," a fictional town based on the real-life Illiers, you will find a reader map based entirely on the text; this reader did not get very far, because the text mentions only the streets that surround the house of the narrator's Aunt Léonie, plus a few others, but without connecting them. Yet another document retrieved by the search shows a complete city map from a book published in 1939, Géographie de Marcel Proust by Alain Ferré. ${ }^{4}$ This map was not derived from the text but created by superposing the places named in the text on a real-world map, a common mapping strategy for narratives that take place in actual locations. ${ }^{5}$ Interestingly enough, a modern Google map of Illiers will show only one of the streets mentioned in Proust - rue St-Hilaire. Yet Ferré's map shows several of these textual streets: for instance, rue de l'Oiseau Fléché, which corresponds, on the current map, to rue du Dr. Gallopin. My guess is that several of the streets mentioned in Proust have been renamed since 1939. In a textualist approach, the maps of Flaubert and Proust would be rejected as a product of the positivism that dominated French criticism until the sixties, but they become worthy of interest if one reads them in terms of the cartographic principles that lead from the textual reality to its graphic representation, as well as in psychological terms, as expressions of the immersive power of storyworlds and of the need of readers to supplement textual information with visual data.

I have so far restricted my discussion to maps of narratives that take place in real-world locations (or more precisely in storyworlds that overlap geographically with the real world), but fantastic narratives, such as Star Wars or Lord of the Rings, have inspired a prolific cartographic activity that often conceives the mapping of storyworlds as an end in itself (Padrón 2007, Hymes 2018). There is for instance no explanatory value to be gained from a map of the Star Wars Galaxy that situates the various planets of the Star Wars universe with respect to each other, because the heroes of the movies teletransport freely from planet to planet,

4 See https://spacefiction.wordpress.com/2014/01/09/a-propos-de-la-geographie-dans-loeuvrede-marcel-proust-a-la-recherche-du-temps-perdu-about-the-geography-in-the-work-of-marcel-pr oust-a-la-recherche-du-temps-perdu/

5 Ironically, any real-world map that associates Combray with Illiers will not account for the location of Combray in Le Temps retrouvé (the last volume of the Recherche), because in this text Proust moves Combray hundred miles east to place it within German artillery range in World War I. 
and distance and proximity plays no strategic role in the plot. ${ }^{6}$ The map is a labor of love, a way for its author to participate in the collective creation of the Star Wars universe. The same can be said of an interactive map of Tolkien's Middle Earth that enables the user to display all the forests, or waterways, or cities by clicking on various buttons. ${ }^{7}$ This map functions for its users as a "prop in a game of make-believe" (Walton 1990) that gives imaginative reality to the storyworld and, through its interactive design, grants them some degree of agency. When the creation of narrative maps constitutes a mode of active participation in storyworlds, the question of the ability of these maps to yield relevant interpretations becomes largely irrelevant.

Let me conclude with a program for narrative cartography: (1) It should be concerned not so much with what readers should do according to certain theoretical paradigms as with what they actually do to deepen and share with others their enjoyment of storyworlds; (2) It should assess the kind of information provided by the map in terms of its contribution to imagining/construing the storyworld; (3) It should bring cartographic scholarship to bear not only on maps of the real world but also on maps of imaginary worlds, by focusing on the strategies of narrative mapping. (4) It should be a part of a larger theory of narrative diagramming.

\section{References}

Denis, Michel. 2018. Space and spatial cognition: A multidisciplinary perspective. London: Routledge.

Jenkins, Henry. 2006. Convergence culture: Where old and new media collide. New York: New York University Press.

Herman, David. 2009. Basic elements of narrative. Oxford: Wiley-Blackwell.

Hymes, Gerald. 2018. Geography and maps. In Mark J. P. Wolf (ed.), The Routledge companion to imaginary worlds, 98-106. London: Routledge.

Nabokov, Vladimir. 1980. Lectures on literature. Ed. Fredson Bowers. New York: Harcourt Brace Jovanovich.

Padrón, Ricardo. 2007. Mapping imaginary worlds. In J.R. Ackerman \& R.W. Karrow, Jr. (eds), Maps: Finding our place in the world, 255-287. Chicago: The University of Chicago Press.

Robbe-Grillet, Alain. 1957. La Jalousie. Paris: Editions de Minuit.

Robbe-Grillet, Alain. 1959. Jealousy. Trans. Richard Howard. New York: Grove Press.

Robbe-Grillet, Alain. 1956. Pour un nouveau roman. Paris: Editions de Minuit.

Robbe-Grillet, Alain. 1963. For a new novel: Essays on fiction. Trans. Richard Howard. New York: Grove Press.

6 This map is located at http://www.swgalaxymap.com/search/

7 See http://lotrproject.com/ 
Ryan, Marie-Laure. 1991. Possible worlds, artificial intelligence and literary theory. Bloomington: Indiana University Press.

Ryan, Marie-Laure. 2016. Narrative as virtual reality 2: Immersion and interactivity in literature and electronic media. Baltimore: Johns Hopkins University Press.

Ryan, Marie-Laure, Kenneth Foote \& Maoz Azaryahu. 2026. Narrating space/spatializing narrative: Where narrative theory and geography meet. Columbus: Ohio State University Press.

Saint-Gelais, Richard. 2011. Fictions transfuges: la transfictionnalité et ses enjeux. Paris: Seuil.

Sternberg, Meir. 1992. Telling in time (II): Chronology, teleology, narrativity. Poetics Today 13(3). 463-541.

Tolkien, J. R. R. 1997. On fairy-stories. In C. Tolkien (ed.), The Monsters and the critics and other essays, 109-162. London: Harper Collins.

Tufféry, G. 2014. La géographie dans "La Recherche” de Proust/Geography in Proust's "In search of lost time". https://spacefiction.wordpress.com/2014/01/09/a-propos-de-la-geographiedans-loeuvre-de-marcel-proust-a-la-recherche-du-temps-perdu-about-the-geography-inthe-work-of-marcel-proust-a-la-recherche-du-temps-perdu/ (accessed 15 Sept. 2018)

Tversky, Barbara. 2003. Structures on mental space: How people think about space. Environment and Behavior 35. 66-80.

Wolf, Mark J. P. 2012. Building imaginary worlds: The theory and history of subcreation. New York: Routledge.

Walsh, Richard. 2017. Beyond fictional worlds: Narrative and spatial cognition. In Per Krogh Hans en, John Pier, Philippe Roussin \& Wolf Schmid (eds.), Emerging vectors of narratology. Berlin: De Gruyter. 461-478.

Walsh, Richard. 2007. The rhetoric of fictionality: Narrative theory and the idea of fiction. Columbus: Ohio State University Press.

Walton, Kendall. 1990. Mimesis as make-believe: On the foundation of the representational arts. Cambridge, MA: Harvard University Press. 